\title{
A model for predicting life expectancy of children with cystic fibrosis
}

\author{
P. Aurora ${ }^{+}$, A. Wade*, P. Whitmore ${ }^{+}$, B. Whitehead ${ }^{+}$
}

\begin{abstract}
A model for predicting life expectancy of children with cystic fibrosis. P. Aurora, A. Wade, $P$. Whitmore, B. Whitehead. C)ERS Journals Ltd 2000.

ABSTRACT: In this study the authors aimed to produce a model for predicting the life expectancy of children with severe cystic fibrosis (CF) lung disease.

The survival of 181 children with severe CF lung disease referred for transplantation assessment 1988-1998 (mean age 11.5 yrs, median survival without transplant 1.9 yrs from date of assessment) were studied. Proportional hazards modelling was used to identify assessment measurements that are of value in predicting longevity.

The resultant model included low height predicted forced expiratory volume in one second (FEV1), low minimum oxygen saturation $\left(\mathrm{S}_{\mathrm{a}}, \mathrm{O}_{2} \mathrm{~min}\right)$ during a 12 -min walk, high age adjusted resting heart rate, young age, female sex, low plasma albumin, and low blood haemoglobin as predictors for poor prognosis. Extrapolation from the model suggests that a 12-yr old male child with an FEV1 of $30 \%$ pred and a $S_{\mathrm{a}}, \mathrm{O}_{2} \min$ of $85 \%$ has a $44 \%$ risk of death within 2 yrs $(95 \%$ confidence interval (CI) $35-54 \%)$, whilst a female child with the same measurements has a $63 \%$ risk of death $(95 \%$ CI $52-73 \%)$ within the same period.
\end{abstract}

The model produced may be of value in predicting the life expectancy of children with severe cystic fibrosis lung disease and in optimizing the timing of lung transplantation.

Eur Respir J 2000; 16: 1056-1060.
${ }^{+}$Cardiorespiratory and Critical Care Directorate, Great Ormond Street Children's Hospital NHS Trust, London, and *Epidemiology and Public Health Unit, Institute of Child Health, London, UK.

Correspondence: P. Aurora, Portex Anaesthesia, Intensive Care and Respiratory Medicine Unit, Institute of Child Health, 30 Guilford Street, London WC1N 1EH UK. Fax: 442078298634

Keywords: Children

cystic fibrosis

paediatrics

prognosis

transplant

Received: November 181999

Accepted after revision June 12000
Current international guidelines recommend considering cystic fibrosis $(\mathrm{CF})$ patients for lung transplantation only if their quality of life is judged to be poor, and their life expectancy is $\leq 2$ yrs [1]. Prediction of life expectancy is therefore, an essential component of lung transplantation assessment, and is performed by reviewing a wide variety of clinical and physiological measurements which have been suggested by survival studies as being of value in predicting prognosis. The most commonly quoted indicator is a forced expiratory volume in one second (FEV1) of $<30 \%$ predicted for height, though young age and female sex suggest a poorer prognosis [2-4]. As life expectancy in CF increases, the data from which these guidelines are derived are increasingly drawn from adult patients, whilst paediatric centres rely on data that may now be of less relevance. There have been no recent survival studies of children with severe CF lung disease in the UK.

The aim of the present study therefore, was to employ proportional hazards modelling to study the survival of CF patients referred to Great Ormond Street Children's Hospital (GOSH) for lung transplantation assessment 1988-1998, and identify those clinical and physiological measurements of most value in predicting survival in paediatric $\mathrm{CF}$ patients with severe lung disease.

\section{Patients and methods}

The study population comprised 181 children with $\mathrm{CF}$ and severe lung disease referred to GOSH for considera- tion of lung transplantation May 1988-February 1998. The guidelines to referral centres during this period were that children would be considered for transplantation if their FEV1 was approaching $30 \%$ pred, and also female children and younger patients would be considered earlier. The majority of the children were referred from other hospitals, and all of them were from the UK or Eire.

All of the children underwent detailed clinical, physiological, and psychosocial assessment soon after referral. Eighteen variables were analysed. FEV1, forced vital capacity (FVC), and peak expiratory flow rate (PEFR) were measured by a Vitalograph Compact spirometer (Vitalograph, Buckinghamshire, UK) using Brompton Predicted scores to correct for height [5]. Minimum oxygen saturation during a 12-min walk $\left(\mathrm{S}_{\mathrm{a}}, \mathrm{O}_{2} \mathrm{~min}\right)$ [6] was measured by continuous pulse oximetry. Distance walked during the test (distance) was also recorded. Resting heart rate (AAHR) was measured by an experienced member of the transplant team in a day ward environment, and then corrected for expected mean for age. Pancreatic exocrine insufficiency was defined as requirement for regular pancreatic enzyme supplementation. Established hepatic disease was defined as hepatic enlargement, fatty infiltration, or cirrhosis detected by ultrasonography. Cepacia colonization was defined as culture of Burkholderia cepacia from a sputum sample or cough swab within the preceding 2 yrs. The method for calculating percentage ideal weight has been recorded elsewhere [7]. Age, sex, blood haemoglobin concentration $(\mathrm{Hb})$, blood leukocyte count (WCC), plasma immunoglobulin-G concentration (IgG), plasma albumin concentration, plasma aspartate 
transaminase concentration (AST), and number of courses of intravenous antibiotics administered to the child in the preceding 6 months (IV frequency) were also recorded. Date of entry to the study was the date of first assessment, and all measurements were taken at this time.

\section{Data analysis}

For all analyses children receiving transplants during the study period were censored from the date of transplant. Survival from date of first assessment was calculated by the Kaplan Meier method. Pearson correlation coefficients were calculated to test relationships between predictor variables. Cox proportional hazards modelling [8] was used to investigate the relationship between variables measured at assessment and survival from date of assessment to transplant (censored), study end (censored), or death. The resultant model was used to predict survival for a series of patient types. The analyses were performed using the Statistical Package for Social Sciences 6.1.3 software (SPSS, Chicago, IL, USA).

\section{Results}

Forty-six patients received transplants during the study period. Of 135 patients not receiving transplants 92 died, and 43 were still alive at study end. Median \pm SEM survival without transplant was calculated as $1.9 \pm 0.35$ SEM yrs from date of first assessment. Patient characteristics are shown in table 1 .

Table 1. - Patient characteristics

\begin{tabular}{|c|c|c|}
\hline Variable & Mean \pm SD & Range \\
\hline $\mathrm{Sa}, \mathrm{O}_{2} \min \%$ & $85.4 \pm 7.6$ & $58.0-95.0$ \\
\hline FEV1 \% & $33.2 \pm 12.3$ & $13.0-75.0$ \\
\hline $\mathrm{FVC} \%$ & $47.1 \pm 18.0$ & $14.0-95.0$ \\
\hline PEFR \% & $54.3 \pm 18.0$ & $15.0-111.0$ \\
\hline Distance walked (m) & $643.0 \pm 367.6$ & $12.0-1440.0$ \\
\hline AAHR \% & $122.4 \pm 20.9$ & $80.0-178.0$ \\
\hline Age yrs & $11.51 \pm 3.08$ & $3.52-18.92$ \\
\hline Sex M/F & $77 / 104$ & \\
\hline WCC $1 \times 10^{9} \cdot \mathrm{L}^{-1}$ & $11.1 \pm 5.1$ & $3.3-37.0$ \\
\hline $\operatorname{IgG~} \mathrm{mmol} \cdot \mathrm{L}^{-1}$ & $16.9 \pm 6.8$ & $1.5-43.8$ \\
\hline Hepatic disease $\mathrm{Y} / \mathrm{N}$ & $26 / 127$ & \\
\hline Albumin $\mathrm{mmol} \cdot \mathrm{L}^{-1}$ & $37.3 \pm 4.2$ & $15.0-49.0$ \\
\hline $\mathrm{Hb} g \cdot \mathrm{dL}^{-1}$ & $13.03 \pm 1.4$ & $7.7-15.6$ \\
\hline IV Frequency no/6 mths & $3.32 \pm 1.7$ & $0-10$ \\
\hline Ideal weight $\%$ & $91.5 \pm 11.8$ & $60.0-134.4$ \\
\hline $\mathrm{AST} \mathrm{iu} \cdot \mathrm{mL}^{-1}$ & $44.8 \pm 24.9$ & $\begin{array}{c}15.0-207 \\
(\text { median } 44.0)\end{array}$ \\
\hline \multicolumn{3}{|l|}{ Pancreatic insufficiency } \\
\hline $\mathrm{Y} / \mathrm{N}$ & $170 / 4$ & \\
\hline \multicolumn{3}{|l|}{ Cepacia colonization } \\
\hline $\mathrm{Y} / \mathrm{N}$ & $19 / 157$ & \\
\hline
\end{tabular}

$\mathrm{Sa}_{\mathrm{a}} \mathrm{O}_{2}$ min: low minimum oxygen saturation during a 12-minute walk; FEV1: forced expiratory volume in one second; FVC: forced vital capacity; PEFR: peak expiratory flow rate; AAHR: resting heart rate; M: male; F: female; WCC: blood leukocyte count; IgG: plasma immunoglobulin-G concentration; $\mathrm{Hb}$ : blood haemoglobin concentration; IV frequency: number of courses of intravenous antibiotics administered to the child in the preceding 6 months; AST: plasma aspartate transaminase concentration.
FEV1, FVC, $\mathrm{S}_{2}, \mathrm{O}_{2}$ min, and distance were noted to be strongly correlated to each other (Pearson Correlation coefficients 0.876 for FVC versus FEV1, 0.577 for $\mathrm{Sa}_{\mathrm{a}} \mathrm{O}_{2}$ min versus $\mathrm{FEV} 1,0.422$ for distance versus $\mathrm{FEV} 1$, 0.546 for $\mathrm{FVC}$ versus $\mathrm{Sa}_{\mathrm{a}} \mathrm{O}_{2} \mathrm{~min}, 0.438$ for $\mathrm{FVC}$ versus distance, 0.380 for $\mathrm{Sa}_{2} \mathrm{O}_{2}$ min versus distance, all two tailed p-values $<0.0005)$, and significantly associated with death within the study period by univariate survival analysis (table 2).

Cox proportional hazards models which included subsets of predictors were compared via consideration of their -2 log likelihood ratios. The "best" model was selected primarily by its statistical significance, although practicality was also considered. A model containing AAHR, $\mathrm{FEV} 1, \mathrm{Sa}_{\mathrm{a}} \mathrm{O}_{2} \mathrm{~min}$, age, sex, albumin, and $\mathrm{Hb}$ was found to give a fit that was not significantly worse than any other similarly sized subset of variables. Partial regression coefficients, standard errors, partial hazard ratios, and pvalues for this final model are given in table 3. High AAHR, low FEV1, low $\mathrm{Sa}_{\mathrm{a}} \mathrm{O}_{2}$ min, young age, female sex, low albumin, and low $\mathrm{Hb}$ were predictors of poor survival.

The covariates and partial regression coefficients from this model were then used to generate a 2-yr survival probability score (SP) where SP is the proportion of patients for any given assessment data expected to survive 2-yrs from time of measurement, expressed as a percentage.

Predicted life expectancy for a series of hypothetical patient types was calculated from the model. The results are shown in table 4 . The predicted survival of patient

Table 2. - Univariate Cox regression analysis

\begin{tabular}{|c|c|c|c|}
\hline Variable & HR & $\begin{array}{l}95 \% \mathrm{CI} \\
\text { of } \mathrm{HR}\end{array}$ & p-value \\
\hline $\mathrm{Sa}_{2} \mathrm{O}_{2} \min \%$ & 0.94 & $0.92-0.96$ & $<0.00005$ \\
\hline FEV1 \% & 0.96 & $0.95-0.98$ & 0.0002 \\
\hline FVC \% & 0.97 & $0.96-0.98$ & $<0.00005$ \\
\hline PEFR \% & 1.00 & $1.00-1.01$ & 0.64 \\
\hline Distance (m) & 1.000 & $0.999-1.000$ & 0.007 \\
\hline AAHR \% & 1.02 & $1.01-1.03$ & 0.0002 \\
\hline Age yrs & 0.95 & $0.88-1.02$ & 0.14 \\
\hline Male sex & 0.89 & $0.58-1.36$ & 0.6 \\
\hline WCC $1 \times 10^{9} \cdot \mathrm{L}^{-1}$ & 1.00 & $0.97-1.05$ & 0.4 \\
\hline $\mathrm{IgG} \mathrm{mmol} \cdot \mathrm{L}^{-1}$ & 1.02 & $0.99-1.05$ & 0.3 \\
\hline Presence of hepatic disease & 0.86 & $0.49-1.5$ & 0.6 \\
\hline Albumin $\mathrm{mmol} \cdot \mathrm{L}^{-1}$ & 0.91 & $0.87-0.96$ & 0.0001 \\
\hline $\mathrm{Hb} g \cdot \mathrm{dL}^{-1}$ & 0.82 & $0.71-0.95$ & 0.007 \\
\hline IV Frequency no/6 mths & 1.13 & $0.98-1.30$ & 0.09 \\
\hline Ideal weight \% & 1.00 & $0.98-1.01$ & 0.5 \\
\hline AST iu $\cdot \mathrm{mL}^{-1}$ & 1.00 & $0.99-1.01$ & 1.0 \\
\hline $\begin{array}{l}\text { Presence of pancreatic } \\
\text { insufficiency }\end{array}$ & 1.18 & $0.29-4.79$ & 0.82 \\
\hline $\begin{array}{l}\text { Presence of cepacia } \\
\text { colonization }\end{array}$ & 1.64 & $0.89-3.05$ & 0.12 \\
\hline
\end{tabular}

$\mathrm{Sa}_{\mathrm{a}} \mathrm{O}_{2}$ min: low minimum oxygen saturation during a 12 minute walk; FEV1: forced expiratory volume in one second; FVC: forced vital capacity; PEFR: peak expiratory flow rate; AAHR: resting heart rate; WCC: blood leukocyte count; IgG: plasma immunoglobulin-G concentration; $\mathrm{Hb}$ : blood haemoglobin concentration; IV frequency: number of courses of intravenous antibiotics administered to the child in the preceding 6 months; AST: plasma aspartate transaminase concentration; HR: hazards ratio; 95\% CI: 95\% confidence interval. 
Table 3. - Predictive model

\begin{tabular}{lrccc}
\hline Variable & \multicolumn{1}{c}{ B } & SEM (B) & HR & p-value \\
\hline AAHR & 0.014 & 0.006 & 1.014 & 0.03 \\
FEV 1 & -0.028 & 0.013 & 0.972 & 0.03 \\
$\mathrm{Sa}_{2}$ min & -0.039 & 0.016 & 0.962 & 0.01 \\
Age & -0.104 & 0.043 & 0.901 & 0.01 \\
Sex & -0.533 & 0.245 & 0.587 & 0.03 \\
Albumin & -0.054 & 0.028 & 0.947 & 0.06 \\
Hb & -0.179 & 0.091 & 0.836 & 0.05 \\
\hline
\end{tabular}

AAHR: resting heart rate; FEV1: forced expiratory volume in one second; $\mathrm{Sa}, \mathrm{O}_{2}$ min: low minimum oxygen saturation during a 12-minute walk; $\mathrm{Hb}$ : haemoglobin concentration; $\mathrm{B}$ : regression coefficient; HR: antilog of B (partial hazard ratio).

type $\mathrm{C}$ (age: 12 yrs; FEV1: 30\%; $\mathrm{Sa}_{\mathrm{a}} \mathrm{O}_{2} \mathrm{~min}: 85 \%$; AAHR: $122.5 \%$; albumin: $\left.37.6 \mathrm{~g} \cdot \mathrm{L}^{-1} \mathrm{Hb}: 13.1 \mathrm{~g} \cdot \mathrm{dL}^{-1}\right)$ is shown in fig. 1. A male child of patient type $\mathrm{C}$ was calculated to have a $44 \%$ risk of death within 2 yrs (95\% CI 35-54\%), whilst a female child of patient type $\mathrm{C}$ was calculated to have a $63 \%$ risk of death within 2 yrs (95\% CI 52-73\%).

\section{Discussion}

Lung and heart/lung transplantation have been available as therapy for end-stage lung disease since the early 1980s, and by $1997>500$ children (<16 yrs) had received lung or heart-lung transplants worldwide. The great majority have been children with CF. The results from the two procedures are similar, and are markedly poorer than for other solid organ transplants, with the International Registry reporting survival of $60-80 \%$ at $1 \mathrm{yr}$ and $30-45 \%$ at 5 yrs for both procedures [9]. The majority of the early deaths are related to acute rejection or overwhelming infection. Obliterative bronchiolitis then develops in the majority of survivors, and is the cause of most late deaths.

With such limited post-transplant survival, the timing of transplantation has become an important clinical decision. At the study centre, the decision to recommend transplantation in children with CF depends on three factors: life expectancy of $\leq 2$ years; poor quality of life; no contraindications to transplantation. The timing of listing for transplantation involves balancing the long waiting time for organs against the expected survival post-transplant. Over the last 10 yrs the median wait for heart-lung transplantation at the Great Ormond Street Hospital is 7 months from date of listing, and patients with life expectancy of less than this at time of acceptance may be less likely to receive organs. It is therefore, currently suggested that patients should be listed when their predicted survival is 7 months -2 yrs, as this allows them a fair chance of receiving organs, whilst also suggesting that transplantation will improve their life expectancy.

Determining life expectancy in children with $\mathrm{CF}$ referred for transplantation assessment is a difficult procedure, and review of a variety of clinical and physiological measurements is preferable to prediction based on lung function measurements alone [10]. Although a number of clinical scoring systems for $\mathrm{CF}$ are in regular usage, these are of limited use in determining life expectancy. There have been previous studies that have employed proportional hazards modelling in order to identify measurements that are of prognostic value in these patients, with particular emphasis on the use of lung function measurements to determine life expectancy. KEREM et al. [2] studied the survival of 673 patients (children and adults) from the Hospital for Sick Children, Toronto, over a 13 yr period (1977-1989). Twenty-eight per cent of the patients died during this time. They identified an FEV1 of $<30 \%$ pred, young age, and female sex as risk factors for death within 2 yrs. The authors also studied the value of percentage ideal weight as a predictor, but found it of little value, particularly in younger patients. HAYLLAR et al. [11] studied 403 patients, predominantly adults, from the Royal Brompton Hospital, London, 1969-1989. This analysis identified FEV1, FVC, height, WCC, clinically detected hepatomegaly, serum albumin and alkaline phosphatase concentrations as the best predictors of survival.

The aim of this study was to produce a practical model that would be of value to CF centres deciding when to refer children for transplant assessment, and to transplant centres deciding when these children are to be listed. The strength of the model therefore, has to be balanced against practical considerations. The final model was chosen as a strong predictor of survival that contains FEV1 as one of the covariates, and because the six other covariates included can be easily recorded during outpatient review.

The initial stepwise analysis selected $\mathrm{Sa}_{\mathrm{a}} \mathrm{O}_{2}$ min and FVC as predictors of survival above FEV1. However, in this group of patients $\mathrm{FEV} 1, \mathrm{FVC}, \mathrm{Sa}_{2} \mathrm{O}_{2} \mathrm{~min}$, and distance walked during exercise test are closely correlated. Replacing FVC with FEV1 in this prognostic model consequently had no significant effect on the predictive power of the model. This close correlation between measures of lung function and exercise tolerance has not been demonstrated in CF patients with mild to moderate lung disease [12], and the authors suggest that it is a feature of patients with severe disease.

This is the first study to examine the relationship between resting heart rate and survival, and this measurement was found to be a valuable predictor. This may be

Table 4. - Proportion of patients surviving 1 and 2 yrs for a series of four hypothetical presentations of either sex

\begin{tabular}{lccccc}
\hline & \multicolumn{2}{c}{ Predicted 1 yr survival $(95 \%$ CI $)$} & & \multicolumn{2}{c}{ Predicted 2 yr survival (95\% CI) } \\
\cline { 2 - 3 } & Male & Female & & Male & Female \\
\hline Patient type A & $0.81(0.76-0.86)$ & $0.70(0.62-0.78)$ & & $0.66(0.58-0.73)$ & $0.49(0.39-0.59)$ \\
Patient type B & $0.78(0.72-0.85)$ & $0.67(0.58-0.76)$ & & $0.62(0.53-0.70)$ & $0.44(0.34-0.55)$ \\
Patient type C & $0.75(0.68-0.82)$ & $0.61(0.52-0.71)$ & & $0.56(0.46-0.65)$ & $0.37(0.27-0.48)$ \\
Patient type D & $0.64(0.55-0.74)$ & $0.48(0.37-0.60)$ & & $0.41(0.31-0.52)$ & $0.23(0.14-0.34)$ \\
\hline
\end{tabular}

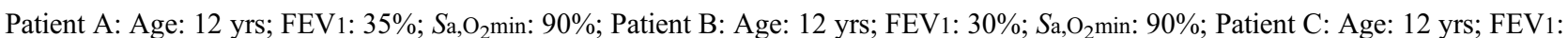
30\%; $\mathrm{Sa}_{\mathrm{a}} \mathrm{O}_{2}$ min: $85 \%$; Patient D: Age: 8 yrs; $\mathrm{FEV} 1$ : $30 \%$; $\mathrm{Sa}_{2} \mathrm{O}_{2} \mathrm{~min}: 85 \%$. For all patients resting heart rate: $122.5 \%$; albumin: $37.6 \mathrm{~g} \cdot \mathrm{L}^{-1}$; Haemoglobin concentration: $13.1 \mathrm{~g} \cdot \mathrm{dL}^{-1}$; CI: confidence interval. 


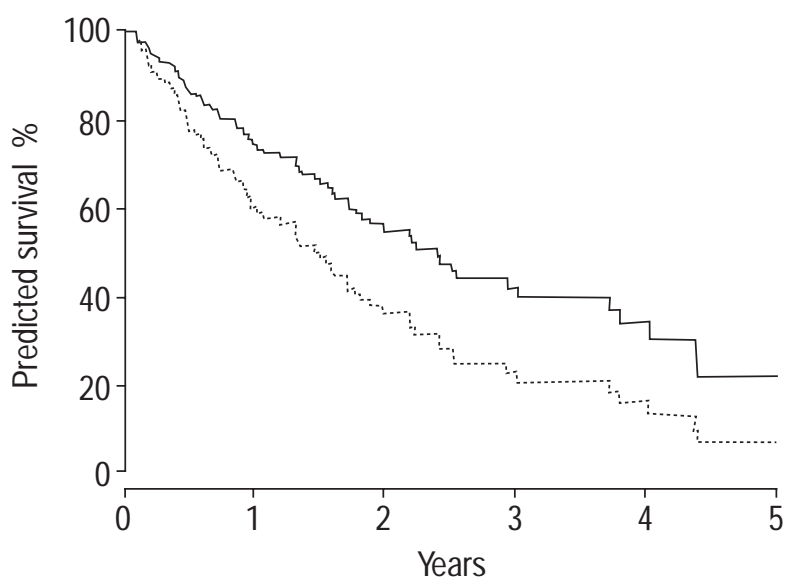

Fig. 1. - Predicted survival of $12 \mathrm{yr}$ old children with a forced expiratory volume in one second of $30 \%$ pred, minimum oxygen saturation during 12-minute walk test of $85 \%$ stratified for sex (resting heart rate, haemaglobin concentration, albumin set at mean for patient population). — : male; - - - -: female.

because resting heart rate is a good marker for energy expenditure (EE) [13], and EE may be of value in measuring disease severity in patients with CF [14]. This relationship appears to be an area that warrants further study, and the use of resting heart rate as a measure of EE may be a valuable tool.

The authors have also shown plasma albumin and $\mathrm{Hb}$ to be predictors for survival. Albumin was included in the model used by HAYLLAR et al. [11], whereas $\mathrm{Hb}$ was suggested as a useful predictor by the initial analysis of their data, but was not included in the final model. The value of albumin and $\mathrm{Hb}$ may be as markers for nutritional status, if so, they appear to be more sensitive in this regard than percentage ideal weight. Two other measures previously suggested to be of value in adult CF patients are height and plasma alkaline phosphatase concentration (ALP) [11]. Height is less easy to analyse in a paediatric population, particularly in a population where delayed puberty is common, and ALP may be a marker for either bone or hepatic disease. The authors did not study either variable.

Many of the other variables included in the initial analysis but not selected for the final model have been demonstrated in previous studies to be of some value in predicting survival in CF $[15,16]$. The data in the present study does not contradict these earlier observations, it is only suggested that in the study population the seven variables included in this model are better predictors of prognosis than the other variables studied.

This final model can be used to predict the survival of individual patients or patient groups who record assessment data similar to those of the study population. Extrapolation from the model suggests that a 12-yr-old male child with an FEV1 of $30 \%$ pred and a minimum oxygen saturation on exercise of $85 \%$ has a $44 \%$ risk of death within 2 yrs (95\% CI 35-54\%), whilst a female child with the same measurements has a $63 \%$ risk of death $(95 \%$ CI $52-73 \%$ ) within the same period. Such calculations assume that the contribution of the seven covariates remains proportional, therefore, employing this model to predict survival for patients whose assessment data falls outside that of the study population is not recommended. Furthermore, this calculation is based on analysis of the authors experience over the last $10 \mathrm{yrs}$, and will become an underestimate of survival as management of patients with end stage lung disease improves.

The authors' prediction is based upon a single assessment of each patient. It has been observed that the rate of decline of FEV1 is a better predictor of prognosis than a single FEV1 measurement [17], and it is possible that this observation will apply to a hazards model employing multiple variables also. Regular reassessment of patients with severe lung disease is therefore, recommended.

The study does contain a possible bias, as it is based on survival analysis of a selected group of patients with CF. The authors are aware that not all children with severe CF lung disease are referred for transplantation assessment, and believe that the majority of those not referred are those who do not wish to consider this option. There are no means of assessing how the survival of these children may differ from those seen in the present study. This bias does not prevent the authors from applying the results to the assessment of future children referred to them, but it should be taken into consideration before applying these results to a broader population.

With these cautions, it is suggested that these results are of value in selecting patients who may benefit from lung transplantation. This study confirms the current recommendations that children with a forced expiratory volume in one second of $30 \%$ predicted should be considered as candidates for transplantation assessment, but females and children $<10$ yrs may need to be referred earlier. In addition, resting tachycardia, desaturation on exercise, low serum albumin, and anaemia should also prompt earlier referral.

\section{References}

1. Maurer JR, Frost EF, Estenne M, Higenbottam T, Glanville AR. International Guidelines for the selection of lung transplant candidates. Transplantation 1998; 66: 951-956.

2. Kerem E, Reisman J, Crey M, Canny GJ, Levison H. Prediction of mortality in patients with cystic fibrosis. $N$ Engl J Med 1992; 326: 87-91.

3. Corey M, Edwards L, Levison H, Knowles M. Longitudinal analysis of pulmonary function decline in patients with cystic fibrosis. J Pediatr 1997; 131: 809-814.

4. Matouk E, Ghezzo RH, Gruber J, Hidvegi R, GrayDonald K. Internal consistency, reliability and predictive validity of a modified $\mathrm{N}$. Huang clinical scoring system in adult cystic fibrosis patients. Eur Respir J 1997; 10: 2004-2013.

5. Rosenthal M, Bain SH, Cramer D, et al. Lung function in white children aged 4 to 19 years: I - Spirometry. Thorax 1993; 48: 794-802.

6. Butland RJA, Pang J, Gross ER, Woodcock AA, Geddes DM. Two-, six-, and 12-minute walking tests in respiratory disease. BMJ 1982; 284: 1607-1608.

7. Kraemer R, Rudeberg A, Hadorn B, Rossi E. Relative underweight in cystic fibrosis and its prognostic value. Acta Paediatr Scand 1978; 33-37.

8. Cox DR, Oakes D. Analysis of Survival Data, London, Chapman and Hall, 1984. 
9. Hosenpud JD, Bennet LE, Keck BM, Fiol B, Novick RJ The Registry of the International Society for Heart and Lung Transplantation: Sixteenth Official Report 1999. J Heart Lung Transplant 1999; 18: 611-626.

10. Doershuk CF, Stern RC. Timing of referral for lung transplantation for cystic fibrosis: overemphasis on FEV1 may adversely affect overall survival. Chest 1999; 115: 782-787.

11. Hayllar KM, Williams SGJ, Wise AE, et al. A prognostic model for the prediction of survival in cystic fibrosis. Thorax 1997; 52: 313-317.

12. Henke KG, Orenstein DM. Oxygen saturation during exercise in cystic fibrosis. Am Rev Respir Dis 1984; 129: 708-711.

13. Hebestrei H, Bar-Or O, McKinty C, Riddell M, Zehr P. Climate-related corrections for improved estimation of energy expenditure from heart rate in children. $J$ Appl Physiol 1995; 79: 47-54.

14. Nixon PA, Orenstein DM, Kelsey SF, Doershuk CF. The prognostic value of exercise testing in patients with cystic fibrosis. N Engl J Med 1992; 327: 1785-1788.

15. Frangolias DD, Mahenthiralingam E, Rae S, et al. Burkholderia cepacia in cystic fibrosis. Variable disease course. Am J Respir Crit Care Med 1999; 160: 15721577.

16. Hodson ME, Morris L, Batten JC. Serum immunoglobulins and immunoglobulin $G$ subclasses in cystic fibrosis related to the clinical state of the patient. Eur Respir J 1988; 1: 701-705.

17. Milla CE, Warwick WJ. Risk of death in cystic fibrosis patients with severely compromised lung function. Chest 1998; 113: 1230-1234. 